\title{
ANALYSIS AND COMPARISON OF A HYDRAULIC AND PNEUMATIC SYSTEM USING THE DYMOLA SOFTWARE
}

\author{
Ângela Cunha ${ }^{1}$, João Veiga², Luís F. Silva ${ }^{3}$,Eurico Seabra ${ }^{4}$ \\ 1,2,3,4 Department of Mechanical Engineering, University of Minho, \\ Campus de Azurém, 4800-058 Guimarães, Portugal \\ A70964@alunos.uminho.pt,A71673@alunos.uminho.pt \\ lffsilva@dem.uminho.pt, eseabra@dem.uminho.pt
}

\begin{abstract}
This work addresses the modelling of a system using Modelica language and the Dymola software tool. Dymola is a modelling and simulation environment that uses the open Modelica language to map hardware components of physical systems directly into software components. Therefore, this modelling language allows the user to model a system in a physical form, rather than a mathematical fashion, through the use of general equations, objects, and links. This paper as an informative character about a tool for the development of mechatronic systems. The topics covered here are part of a more extensive modelling and simulation work on the dynamics of mechanical systems, within the scope of an Integrated Master in Mechanical Engineering. This study was carried out based on the comparison between pneumatic and hydraulic models of the same system. Therefore, it was modeled a system used in backhoe loaders that can be operated either using a hydraulic or a pneumatic cylinder. The activity focuses, essentially, on the analysis of parameters that describe the behaviour of the system, emphasizing the position, velocity, acceleration and loads observed in both cylinders. The goal is to introduce the reader to the Dymola environment and Modelica language by addressing the modelling of a system. This study also pretends to identify significant differences regarding the behaviour performance of the pneumatic and hydraulic approaches to model the selected system, and the causes that lead to such differences.
\end{abstract}

Keywords: Modelica language, Dymola, Dynamic analysis, Modelling by blocks, Mechatronic systems.

\section{Introduction}

Dymola software was developed by Hilding Elmqvist at the Technical University of Lund in Sweden during his PhD. Since then, Dymola / Modelica has evolved into the best and most flexible modelling environment, with respect to the physical system description currently available in the software market.

Several research works can be found in literature using the Dymola software related with the study of complex dynamic systems for modelling and simulate the physical plant and the controllers [1-3]. On other hand, it can also be found other programming languages, namely Matlab, with the same purposes $[4,5]$. The main objective of modelling is to better understand the system's behaviour, enabling the improvement of mechatronic systems in order to obtain safe controllers and optimized physical plants [6-11].

The case study will be based on the analysis of the same system, but acted in two different ways.
In the first case, the action will be hydraulic while in the second, it will be pneumatic.

The developed study involves two basic steps. The first consists in the system's modelling, where all elements that constitute the system, as well as their connections, are selected and the initial parameters are determined; the second addresses the simulation and can be divided into two points: the graphics and the animation. With regard to graphical analysis, the output parameters can be selected to infer about the system behaviour. In terms of animation, the "reaction" of the model is verified against the parameters previously defined in the modelling.

In the light of these two basic steps that constitute an analysis in Dymola software, it can be ensured that this tool allows the analysis of the behaviour of any system.

\section{Used Tool - Software Dymola}

Since the invention of the computer, modelling and simulation have been important aspects in the 
computing area. Dymola software was one of those developed software packages with the aim of covering the two aforementioned areas. It should be noted that it was developed as part of a $\mathrm{PhD}$ thesis by HildingElmqvist in Sweden.

Dymola software consists in a modelling and simulation environment based on the Modelica language. Modelica is a language that allows to model the dynamic behavior of physical systems, which can be composed by mechanical, electrical, hydraulic or pneumatic components, among others. Therefore, it uses libraries to define the components for modelling the systems that can be simulated later, obtaining results of the several variables under study in that particular system [9].

\subsection{Dymola Software Overview}

Dymola software, as previously mentioned, is a modelling and simulation environment based on the Modelica modelling language. Therefore, it can be stated that it is based on the modelling of physical systems through the use of blocks. There are two main areas that must be highlighted in this software: (i) the modelling area and (ii) the simulation area. The software version is Dymola 6.0b[13].

\subsubsection{Software map and functionalities}

As mentioned, the program has two working modes, so the main aspects associated with each one of these modes will be highlighted in this section [8].

The modelling panel (as presented in Figure 1) appears as the program starts. This mode is used for the development of system models by using the components found in the provided software libraries [12]. In this modelling panel, four main areas can be highlighted as depicted in Figure 1. The library window (in the red box) provides all the components (mechanical, electrical, thermal, etc.) that will be combined to form the physical system. The hierarchy of the components (highlighted by the purple box) shows the structure of the overall system and the hierarchical level of its components. The editing tools (placed inside the green box) allows the introduction of small notes, colour manipulation, toggle grid on or off and toggle connect mode [12].

Finally, the visualization mode (in the blue box) allows the checking and visualization of the system in different ways, for example: the button on the left hand side enables the user to edit the way the model is seen when used as a block/sub-model of another system; the second button (from the left hand side) activates the modelling environment, the mode where components can be placed and connected to form the model; the third button is merely used for information purposes, indicating, for example, the name of the file, file path, libraries and software version used; the fourth button allows the user to see the code that implements the defined model.
Here the user can edit and write its own code. However, on the models' level the user cannot see the code of each element, but instead the components used and its connections. By opening a component, it is possible to see its code [13].

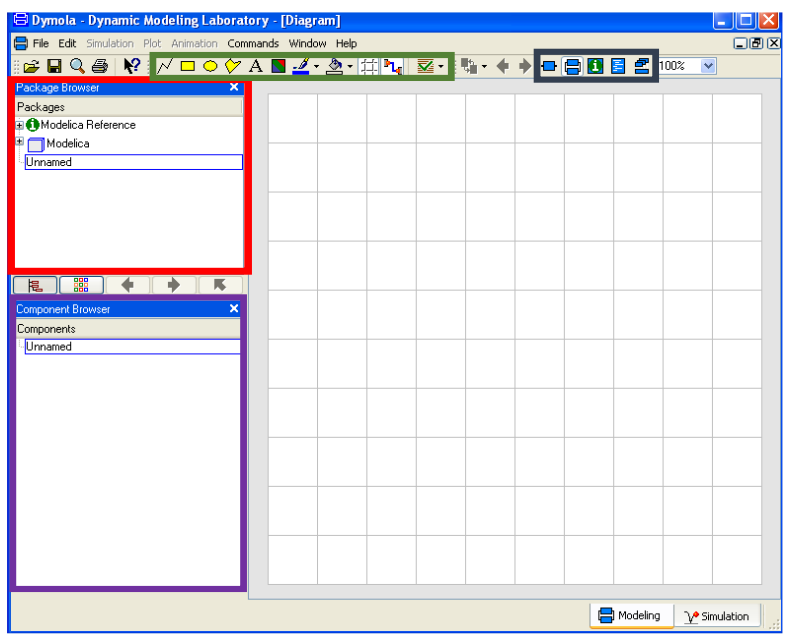

Figure 1: The modelling panel

The simulation mode is used to simulate the developed model, to obtain graphical results and to visualize the behavior and performance of the model through different animations (see Figure 2).

In this mode four main areas can be referred: the variables window (highlighted by the red box) allows the user to check all the variables that can be analyzed and plotted as graphs; the control of simulation (included in the purple box) enables the simulation itself and the change of the simulation parameters, such as time, tolerances and algorithm, for example; the 3D animation controls (presented in the green box) deal with aspects such as start and pause of the animation, elapsed time and speed of the animation; finally, the graphics control (in the blue box) enables the user to insert and delete graphics, change display modes, etc. [12].

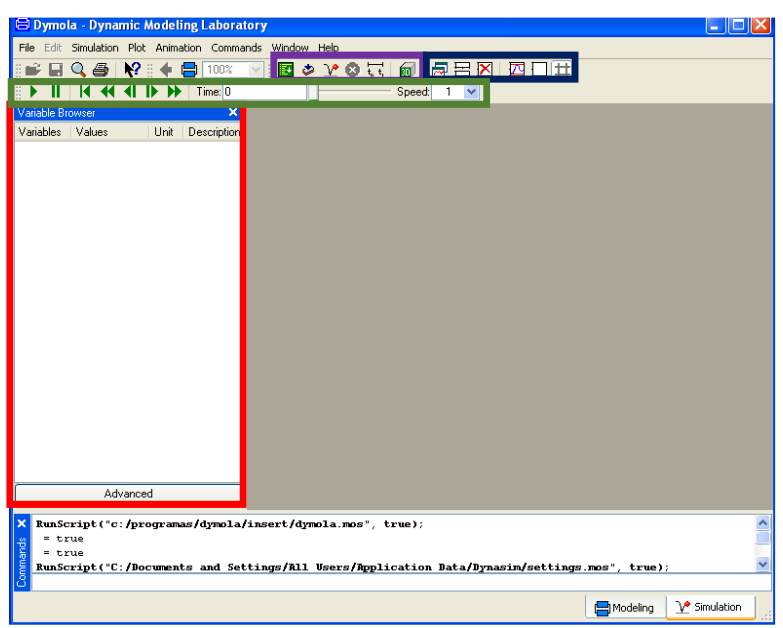

Figure 2: The simulation panel 


\subsection{Constraints and benefits}

In the engineering area, dynamic systems are generally described by differential equations.

Techniques such as the Laplace transform are used to solve these equations, in order to transform the differential equations into algebraic equations, moving from the time domain to the complex numbers domain and vice-versa. This method is the so-called analytical form. In practice, applying this technique to complex systems is very difficult and time consuming. Furthermore, the obtained results are, usually, complex equations with trigonometric functions.

Dymola and similar software use numeric forms of calculation to obtain results of dynamic systems. This software allows a simple modelling of the system by manipulating blocks that represents components of the various engineering areas, simplifying the engineer's task during systems modelling. However, it does not obtain the analytical expressions of the systems' response, relative to the differential equations that model them. However, other tools such as Matlab provide this particular feature. In fact, the Matlab command line provides features to compute the Laplace transforms of the differential equations that model the system and, after obtaining the Laplace transforms, the corresponding inverse Laplace transforms, enabling the analysis of the analytical responses in the time domain.

In practice, the calculation of the analytical results is rarely performed, since it usually generates, as mentioned, very complex equations. The most common approach is to carry out several interpolations to the system to be designed, forcing the resolution of the differential equations with different parameters or solving similar equations. This way, computational analysis becomes more practical and the advantage of having a block-shaped system simplifies the task of changing components' parameters and the system itself.

Taking into account that this software uses numerical methods to obtain results, these will always be close to the analytical solutions. In practice, the analytical result itself is an approximation of the actual physical behavior, since the differential equations that model the physical systems are not exact, being, in general, impossible to measure all the parameters of a system with infinite precision and maintain them constantly updated. The degree of correlation between "theoretical" results and actual physical behavior depends on the degree of correlation between the mathematical model (described by the differential equations) and the physical system. In addition to errors intrinsic to the correlation between the mathematical model and the physical model, there are errors associated with the numerical methods used.

\section{Case study}

Hydraulic and pneumatic systems are very important in mechatronics. These can be found in numerous applications and can be used to provide linear or rotary movements.

In order to determine the difference between the hydraulic and pneumatic actuation, the same system was adopted for the two studied cases and the differences were verified and discussed. Thus, hydraulic and pneumatic cylinders and their respective systems will be analyzed in this section. The first one allows extremely high loads and enable precise and stable positioning, but generally operates at reduced speeds. The second one is simpler, cleaner and can also be found in reduced sizes. The fact that pneumatic actuators work with a compressible fluid makes them better at absorbing impact, but they are, however, less stable in maintaining their position.

The system that will be presented and analyzed in this section comprises a translational joint actuated by a cylinder, hydraulic or pneumatic. This type of connection can be found in the arms of backhoe loaders, for example. However, these is just a demonstrative example and do not intend to model a real mechanism.

\subsection{Hydraulic System}

The overall system consists of several components, including a hydraulic pump, a tank, a directional valve, a hydraulic cylinder, two cylindrical bars, three revolution joints and a translation joint. In addition, two boolean inputs were used connected to the directional valve. It should be noted that all these components have parameters that can be defined previously. In Dymola, by double clicking on a component a window with the properties of the block appear and the user can now define the physical properties or variables, called parameters, of the component, its animation settings and other properties when applicable. For each physical property a comment is provided, giving an instruction of that particular parameter.

As mentioned, Dymola works by connecting different blocks. These blocks are grouped into categories and each block has its own connections. These connections can be of different categories. For example, a translational joint has frames and flanges connections (see Figure 3).

Other joints, such as actuated revolute joints, also have these two types of connections, but with circle flanges. Each connection as its own shape enabling the user to identify immediately what type of connections can be made and where to connect the components. 
Since the cylinder is intended to act on the translational joint, the connection must be carried out as shown in Figure 3, connecting the housing to the fixed part of the joint (flange_b) and the rod acting on the joint in flange_a [14].

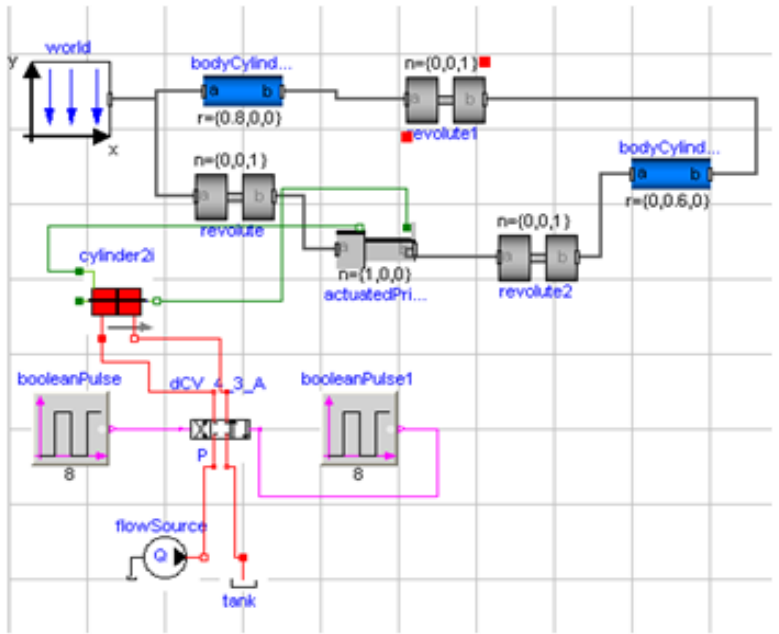

Figure 3: Model of the joint operated by the hydraulic system

\subsubsection{Properties}

Considering the overall system, the defined variables were the pump flow $(1 \mathrm{l} / \mathrm{s})$, cylinder rod length $(800 \mathrm{~mm})$, housing length $(800 \mathrm{~mm})$, piston area $(8110 \mathrm{~mm} 2)$, the piston mass $(4 \mathrm{~kg})$, the diameter of the bars $(200 \mathrm{~mm})$ and their length $(800$ and $1400 \mathrm{~mm}$, respectively). The connection between the bars is located at one end of bar 1 and at $600 \mathrm{~mm}$ from the end of the second bar, which is actuated by the cylinder (see Figure 4 ).

It should be noted that all the other properties not mentioned here were considered as the default values assigned by the software.

\subsubsection{Results}

Considering the previously defined properties, the following representation was obtained (see again Figure 4).

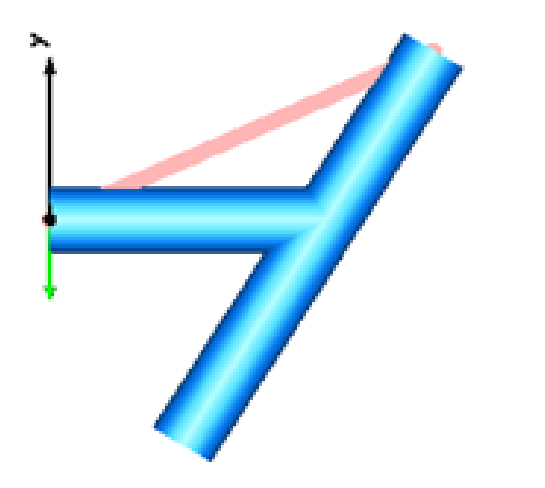

Figure 4: Hydraulic actuated system
The sequence of movements was defined as the following: in the first second the cylinder piston rod moves back (the Boolean Pulse is ON); a second later the directional valve sits in its central position (both boolean entries are OFF), and, over the next second, the cylinder piston rod advances (the booleanPulse 1 is $\mathrm{ON}$ ).

Initially the piston rod is advanced in a central position. The initial position of the flange_b is 1.225 $\mathrm{m}$, which corresponds to the defined center position (see Figure 5). As can be observed, there is an initial backward movement of the piston rod in the first second. When the directional valve is in its central position, the cylinder maintains a constant and stable position. Between the second and the third second, the cylinder piston rod advance is equal to the initial backward motion (the time spent to carry out both motions are the same and the pump output remains constant).

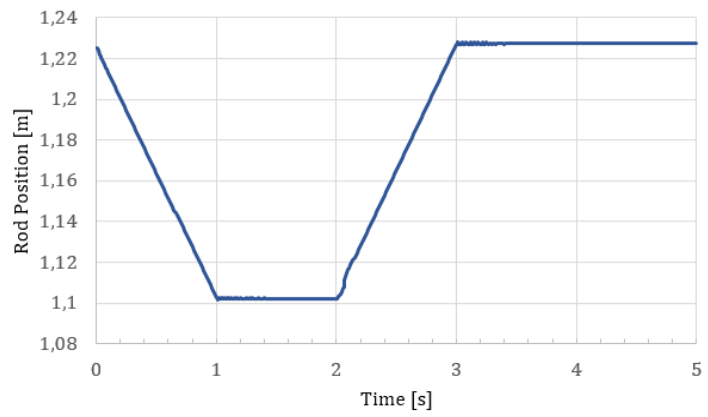

Figure 5: Cylinder piston rod position

Regarding the piston rod velocity, it can be referred that it is approximately constant, except at the beginning or change of motion direction (see Figure 6). In hydraulics, the advance velocity of the piston rod is obtained almost exclusively on the fluid flow inside the cylinder chamber. When the directional valve is not in its central position, the piston rod velocity should be approximately 0.12 $\mathrm{m} / \mathrm{s}$.

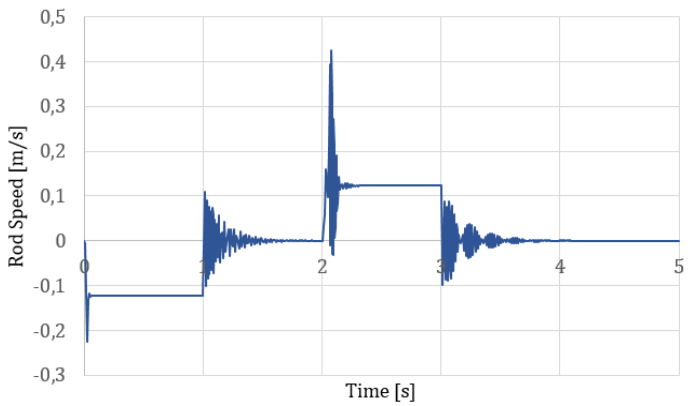

Figure 6: Piston rod velocity (flange_b)

The incompressibility of the fluid generates velocity levels, maintaining constant velocities in each level. The negative part of velocity levels are the high accelerations and vibrations experienced at the beginning, end and during the change of the piston rod motion (see Figure 7). 


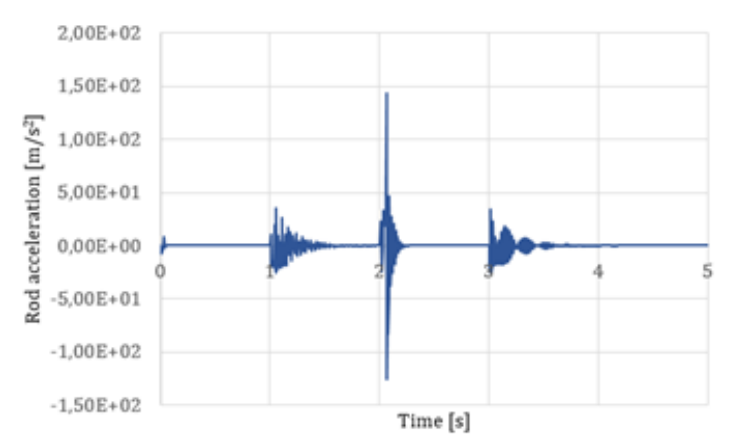

Figure 7: Piston rod acceleration (flange_b)

Dymola Software allows, not only to obtain data of kinematics and Dynamics such as position and its derivatives, but as well loads Figure 8. Knowing the loads on the connections allows the user to carry out a dimensioning with more precision. The loads on the links depend not only on the acceleration that the masses experience in each movement, but also on external loads, such as the weight of the components, friction, etc.

In the example of hydraulics, we can see that the maximum loads depend almost exclusively on the accelerations, since they are very high, at the moments of beginning, end or change of movement (Figure 8). When the movement stabilizes, the loads depend almost exclusively on external forces, since the velocity is practically constant. The Figure 9 shows the accelerations between $0.1 \mathrm{~s}$ and $0.8 \mathrm{~s}$, where it is possible to see that in hydraulic cylinders during the movement of the rod the acceleration of the same is practically nonexistent.

The Figure10 shows the loads on the cylinder rod which increase in modulus with their recoil, looking at Fig. 4, notice that during this movement the angle of the second bar with the vertical axis, according to which gravity acts, increases, once that the center of gravity of this second bar does not coincide with the joint that connects it to the other bar, a load appears in the connection with the rod and it is this external load which is the most responsible for the total.

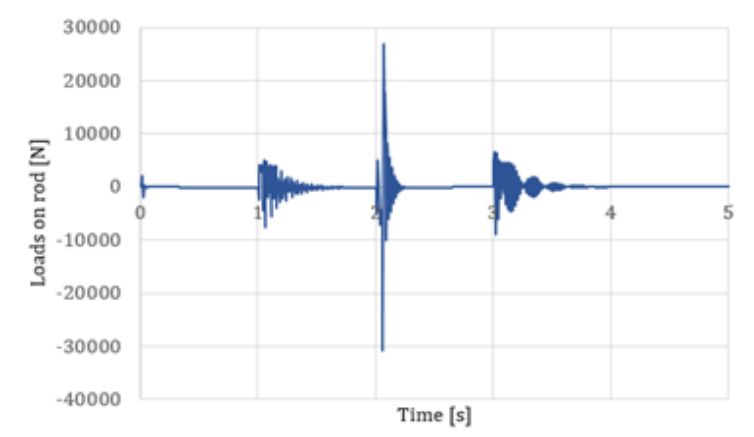

Figure 8: Loads on the cylinder's rod

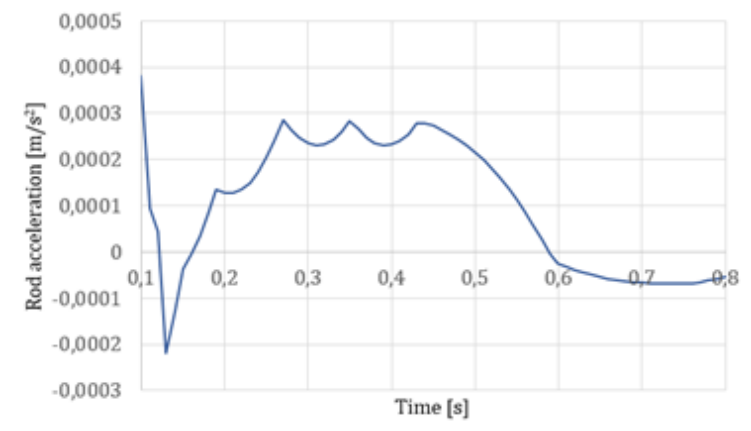

Figure 9: Rod acceleration between 0.1 and 0.8 seconds

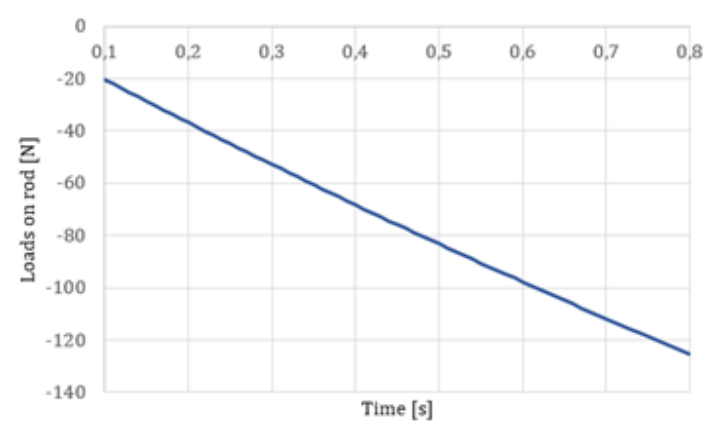

Figure 10: Loads on rod between 0.1 and 0.8 seconds

\subsection{Pneumatic System}

The system depicted in Figure 11 consists of several components including two silencers, a reservoir, a pressure sensor, a directional valve and a pneumatic cylinder. The components of the mechanics group were the same as the ones considered for the hydraulic system. In addition, two boolean inputs were used connected to the directional valve.

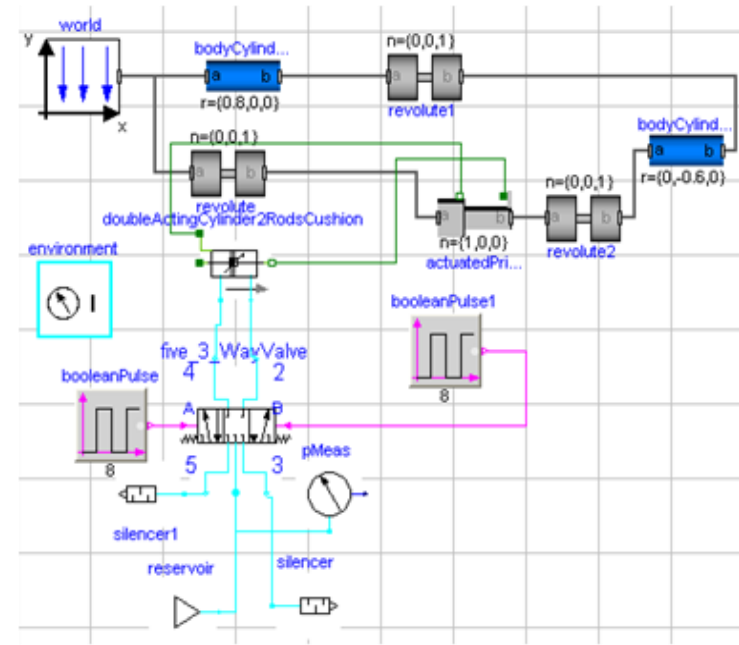

Figure 11: Model of the joint operated by the pneumatic system 


\subsubsection{Properties}

The dimensions of the pneumatic cylinder and the mass of the piston remained the same as those of the hydraulic cylinder. As in the previous example, the same values were considered for the elements of the mechanics group (bars and joints). The objective is to analyze the differences between the two systems. For all the other components, the default values assigned by the software were considered for all the parameters, except for pressure that was set to $0.5 \mathrm{MPa}$.

\subsubsection{Results}

The sequence of movements is the same as the one considered in the previous example. The backward movement of the piston rod occurs in the first second; it stops in the $2^{\text {nd }}$ second, and advances in the third second.

The graph displayed in Figure 12 shows the position of the piston rod over time. It can be observed that the rod's position isn't precise.

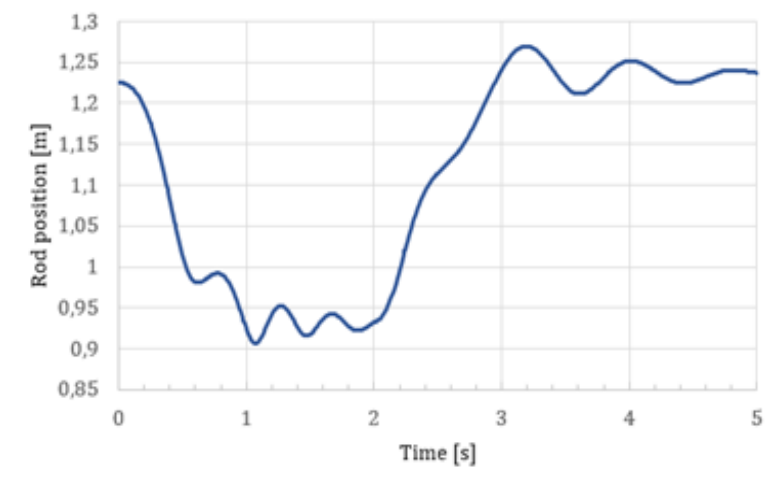

Figure 12: Piston rod position

Although the air flow has ceased between the first and second seconds, the rod does not stop maintaining a precise position. The speed of the piston rod due to the first second (as well as its mass and moving masses connected to the rod), and possible differences between the pressure on each chamber when the valve changes to mid-position, plays an important role here. In the example, the rod and the moving masses have sufficient kinematic energy to compress the air in one of the chambers and expand it on the other continuing the rods movement for a small time even after the air flow has ceased, some of the initial kinematic energy has been loss but a part of it is "stored" as potential energy in the air due to pressure difference between the chambers when the rod reaches zero speed.

This behavior is due to the condition of flow, pressure, inertia and external forces during the previous movement and during the first to the second seconds. Unlike hydraulics properties such as speed of the masses, momentum and external loads have a significant importance on the behavior of the pneumatic actuator, not only when trying to stop it at mid stroke but as well during its movement.

In the example, the pressure difference between chambers results in a force with opposite direction of the previous movement, accelerating the rod and connected masses again and resulting in an oscillatory movement until it stabilizes.

The graph of Figure 13 shows the pressure inside the chamber $\mathrm{A}$ of the cylinder (chamber opposite to the piston rod that acts on the joint), where it is found that the pressure increases with oscillations during the backward movement of the cylinder piston rod.

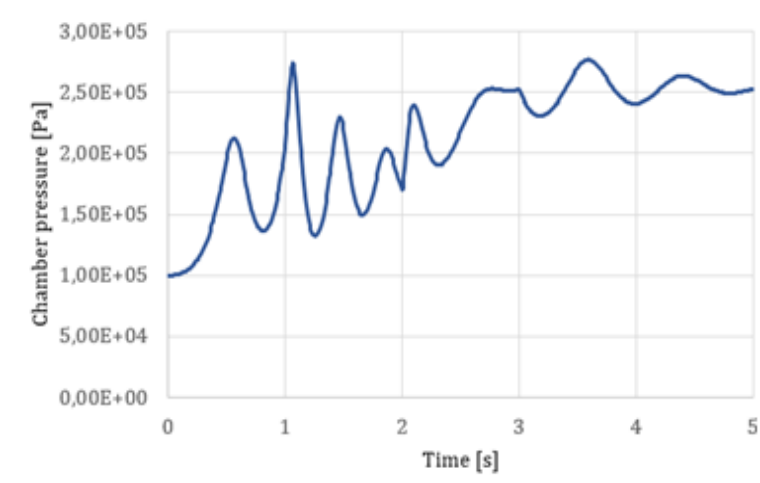

Figure 13: Cylinder chamber pressure

Due to the compressibility of the air, the backward and advance velocity of the cylinder piston rod is not constant (see Figure 14).

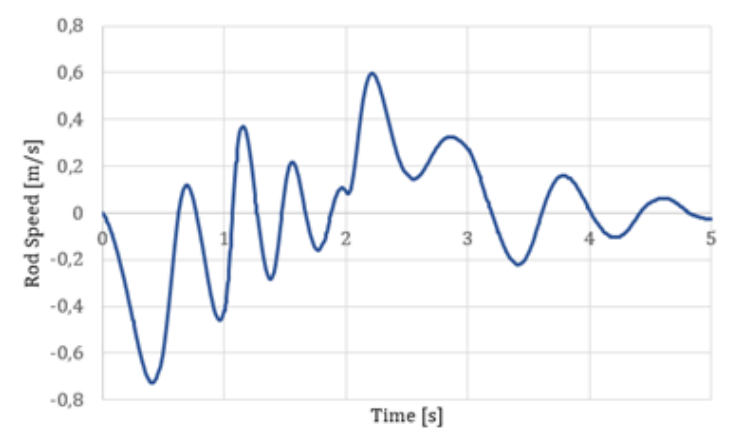

Figure 14: Velocity of the cylinder piston rod

In pneumatics, the accelerations at the beginning and end of movement are not so abrupt.

However, as seen the pressure in the chambers are quite unstable generating loads well above those required to provide the desired motion in a smoother, non-oscillating way, Figure 15.

A good control can decrease the oscillations in the movement, reducing the accelerations and the loads in the joints of the pneumatic cylinder. Unlike what happens in hydraulic systems, in pneumatic the 
external loads will always have influence in the movement of the rod.

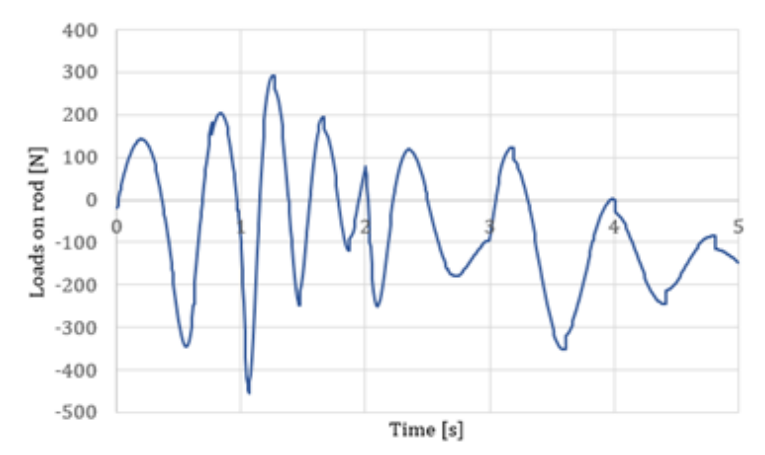

Figure 15: Loads at the cylinder's rod

\section{Results and discussion}

From the graphs displayed in the previous section, it is possible to observe differences between the hydraulic and the pneumatic actuation.

Pneumatic cylinders are more commonly used only to obtain two positions, corresponding to the forward and backward positions of the piston rod, and the directional valves have only two working positions. Even when the piston rod of the cylinder is full advanced, the advancing chamber is still connected to the compressed air supply and the pressure inside this chamber increases to a maximum pressure (which is not the case in this example). In this example it can be observed the oscillations and the lack of precision experienced by the piston rod when trying to stop a pneumatic cylinder during its movement. In applications where it is needed the use of a pneumatic system and it is intended that the piston rod should stop in a precise position during its course, it is essential to carry out a study with the use of a simulation tool like Dymola and special attention should be addressed to the parameters involved (pressures, positions, velocities, ...).

It is possible to optimize the pneumatic solution and its control. While developing a solution it is possible that the mechanical parts may change, changing therefore the operating conditions of the pneumatic cylinder. So it is necessary to solve several interpolations until the desired global characteristics of the system are reached.

Hydraulic cylinders are actually stable for intermediate positions. However, its incompressibility generates high accelerations when the movement is discontinued, that is, when the forward and backward movements begin. In the design of a hydraulic system it may be necessary to determine and verify the ranges of accelerations and vibrations and to select the most adequate components in order to minimize or to avoid some of these disadvantages.

\section{Conclusions}

The purpose of the analysis was to verify the differences between the hydraulic and pneumatic actuation of the same system, but, more than that, to check the calculations and obtaining results provided by the Dymola software.

In relation to the models studied, it was possible to verify that the hydraulic actuation enables a precise positioning, producing constant velocities, but, at the same time, it can generate accelerations and vibrations at the start and at the end of the forward and backward movements. A pneumatic actuation has a smoother start and end movements, but the position control of the intermediate positions (apart from the ones corresponding to the full forward and backward cylinder piston rod positions) and velocity control are very difficult to determine.

Dynamic system analysis is one of the initial design tasks and one of the final tasks of a project. When designing an actuation system it is necessary to make an initial draft of that system without detailed or definitive sizing, to test its kinematics and dynamics. Verify that the system accomplishes the intended task within a desired performance before moving on to the specific areas of the subsystems that make up the overall system, especially in mechatronics systems or any other multidisciplinary system. Initially it enables the evaluation of the loads generated by the components accelerations and verifies if the initial model is able to accomplish the intended task.

In a final phase, it is important to verify and validate, after scaling the subsystems, their operation and the way they work together to accomplish the final intended outcome. An example of this is a pneumatic servomechanism, where in the initial phase the values of accelerations, loads and movements are obtained for the pneumatic cylinder and mechanical skeleton assembly. From these values the mechanical equipment is designed and developed, as well as the pneumatic circuit and its electrical control.

After obtaining the solutions in each one of the development areas, new dynamics simulations will be performed with all the subsystems together in the global system, to check new working load ranges, different accelerations, and to check if the control results are in accordance with the desired kinematics or to validate final adjustments and optimizations.

Modelica and other softwares tools like Dymola enables designers and engineers to go through all the design and development phases in a simple and practical way, easing the change of the components properties present in the designing system and enabling the achievement of results over a huge range of physical properties, from current in a circuit 
to pressures in actuation (hydraulic or pneumatic) cylinders, accelerations of a component or temperature of a fluid.

\section{References}

[1] Machado, J., Seabra, E., Campos, J.C., Soares, F., Leão, C.P. (2011). "Safe controllers design for industrial automation systems", Computers and Industrial Engineering, 60 (4), pp. 635-653. DOI: 10.1016/j.cie.2010.12.020.

[2] Seabra, E., Machado, J. (2010). "Using Modelica modelling language for physical plant parameters evaluation and optimization: A case study", ICINCO 2010 - Proceedings of the 7th International Conference on Informatics in Control, Automation and Robotics, 1, pp. 199205.

[3] Seabra, E., Machado, J. (2011). "Using advanced simulation techniques to improve industrial controller's dependability", IEEE International Conference on Industrial Informatics (INDIN), art. no. 6034848, pp. 122-127. DOI: 10.1109/INDIN.2011.6034848.

[4] Costa, J., Seabra, E., Puga, H. (2016). "Modelação e otimização de centrais óleo-hidráulicas servo acionadas autónomas", Proceedings of XX InternationalCongresson Project Engineering, Cartagena, Spain, 2016, 8p.

[5] Seabra, E., Costa, J., Puga, H., Leão, C. (2016). "Matlab simulation of autonomous servo driven oil-hydraulic power unit, paper", IMECE201666582, Proceedings of ASME Conf. Proc. IMECE2016, Phoenix, AZ, USA, 7p.

[6] Cellier, F., Greifeneder, J. (1991). “Continuous System Modeling”, 1st ed., Arizona, ISBN: 978-14757-3924-4.
[7] Seabra, E., Silva, L.F, Silva, F., Vieira, J. (2016). "Modelica como uma linguagem de engenharia Modelação de sistemas mecânicos/ mecatrónicos", 2 ${ }^{\text {a }}$ Conferência Internacional da Sociedade Portuguesa para a Educação e Engenharia (CISPEE 2016), Vila Real, 8p.

[8] Vieira, J., Silva, F. (2016). "Utilização da linguagem e da tecnologia Modelica para o desenvolvimento baseado em modelos", Department of Mechanical Engineering, University of Minho.

[9] Campos, J.C., Machado, J., Seabra, E. (2008) "Property patterns for the formal verification of automated production systems". IFAC Proceedings Volumes (IFAC-PapersOnline), 17 (1 Part 1)

[10] Kunz, G., Perondi, E., Machado, J. (2011) "Modeling and simulating the controller behavior of an Automated People Mover using IEC 61850 communication requirements". IEEE International Conference on Industrial Informatics (INDIN), art. no. 6034947, pp. 603608

[11] Campos, J.C., Machado, J. (2009) "Pattern-based analysis of automated production systems". IFAC Proceedings Volumes (IFAC-Papers Online), 13 (PART 1), pp. 972-977

[12] Höbinger, M., Otter M. (2008). "PlanarMultiBody - A Modelica Library for Planar Multi-Body Systems", In Proceedings of the 6th International Modelica Conference, Modelica' 2008, Bielefeld, Germany.

[13] Elmqvist, H., Brück, D., Otter, M. (1996). "Dymola - User's Manual", Dynasim AB, Research Park Ideon, Lund, Sweden.

[14] Theurillat, R.S. (2011). "Modeling and Simulation of Hydraulic Systems in Dymola/ Modelica by Means of Bond Graphs", In Modeling and Simulation Research Group, Zurich. 